\title{
Oxygen- and Water-Induced Energetics Degradation in Organometal Halide Perovskites
}

J ianming Yang, Zhongcheng Yuan, Xianjie Liu, Slawomir Braun, Yanqing Li, J ianxin Tang, Feng Gao, Chungang Duan, Mats Fahlman and Qinye Bao

The self-archived postprint version of this journal article is available at Linköping University Institutional Repository (DiVA):

http:// urn.kb.se/ resolve?urn=urn:nbn:se:liu:diva-148390

N.B.: When citing this work, cite the original publication.

Yang, J., Yuan, Z., Liu, X., Braun, S., Li, Y., Tang, J., Gao, F., Duan, C., Fahlman, M., Bao, Q., (2018),

Oxygen- and Water-Induced Energetics Degradation in Organometal Halide Perovskites, ACS Applied Materials and Interfaces, 10(18), 16225-16230. https:// doi.org/ 10.1021/ acsami.8b04182

Original publication available at:

https:// doi.org/ 10.1021/acsami.8b04182

Copyright: American Chemical Society

http:// pubs.acs.org/ 
Oxygen- and Water-induced Energetics Degradation in Organometal Halide Perovskites

Jianming Yang, "\# Zhongcheng Yuan ${ }^{2},{ }^{\#}$ Xianjie Liü, Slawomir Braun ${ }^{3}$, Yanqing $\mathrm{Li}^{4}$, Jianxin Tang ${ }^{4}$, Feng Gao $^{2}$, Chungang Duan ${ }^{1,5}$, Mats Fahlman ${ }^{3}$, Qinye Bao ${ }^{1,2 *}$

1 Key Laboratory of Polar Materials and Devices, Ministry of Education, East China Normal University, 200241, Shanghai, P.R. China

E-mail: qybao@clpm.ecnu.edu.cn

2 Division of Biomolecular and Organic Electronics, IFM, Linköping University SE58183 Linköping, Sweden

3 Division of Surface Physics and Chemistry, IFM, Linköping University SE-58183 Linköping, Sweden

4 Institute of Functional Nano \& Soft Materials (FUNSOM), Soochow University, Suzhou 215123, P. R. China

5 Collaborative Innovation Center of Extreme Optics, Shanxi University, Taiyuan, Shanxi, 030006, P.R. China

\# The authors contributed equally to this work.

Keywords: organometal halide perovskites; energetics; oxygen/water; in-situ; degradation 


\begin{abstract}
Organometal halide perovskites are under rapid development and significant focus has been placed on their stability that currently presents a major obstacle for practical application. The energetics play a vital role in charge injection/extraction and transport properties in devices. Here, we in-situ investigate oxygen and water-induced energetic degradation in organometal halide perovskite films. Oxygen gas induces an upwards shift of the vacuum level of the perovskite films due to the formation of an oxygeninduced surface dipole and water vapor causes vacuum level significant downshift as well as the valence band binding energy referenced to Fermi level simultaneously increase so as to keep the ionization potential of the perovskite films unchanged. Moreover, the chemical compositions, crystalline structures, surface morphologies and dynamical properties also are monitored and analyzed in detail. These results are indispensable to understand the degradation mechanisms and to in future perform the optimizations of the sable materials and devices.
\end{abstract}




\section{Introduction}

Organometal halide perovskites, i.e. $\mathrm{CH}_{3} \mathrm{NH}_{3} \mathrm{PbI}_{3}$ and $\mathrm{CH}_{3} \mathrm{NH}_{3} \mathrm{PbI}_{3-\mathrm{x}} \mathrm{Cl}_{x}$, have recently attracted tremendous attention as candidates for the next-generation solar cells because of their excellent performance. ${ }^{1-6}$ This kind of hybrid organic-inorganic perovskite exhibits large absorption coefficient, tunable band gap, long carrier diffusion length and ambipolar charge transport, which are the prerequisite to high efficiency photovoltaic devices. ${ }^{7-10}$ Much effort has been invested in perovskite materials processing and device architecture design, and the power conversion efficiency of the perovskite-based photovoltaic cells has achieved over $20 \%$ in singlejunction cells. ${ }^{11-13}$ Its theoretical maximum is expected to be larger than $30 \%$ and this can beat the efficiency of the conventional silicon cell $\sim 25 \%{ }^{14}$ Despite impressive development in device efficiency, a critical issue of the perovskite device remains: stability. The device performance typically degrades quickly when exposed to oxygen, water, light and elevated temperature, leading to the large decrease in short-circuit current, open-circuit voltage and fill factor. ${ }^{15-18}$ The device efficiency as a function of aging time especially shows initially a fast and severe loss in the first dozens of hours, which is termed "burn-in”. ${ }^{11,19}$ The burn-in degradation could result in a loss of over $20 \%$ of the initial efficiency. ${ }^{15,20}$ Additionally, several studies have also pointed out that the perovskite material itself, especially the lead-based and the organic constituents, will decompose into other species causing a loss of the desired photovoltaic properties under the different conditions. ${ }^{21-24}$ These intrinsic instabilities of the perovskite materials and the corresponding devices present a major challenge for application on a commercial scale. 
The electronic structures and interface energetics play a critical role in the device efficiency, governing the charge injection/extraction and transport properties at contacts. ${ }^{25-30}$ However, there is so far few reports on the influence of ambient atmosphere on the surface energy structures of perovskites, which is an prerequisite to understand the degradation mechanisms, and to in future optimize the materials and devices. The position of the valence band and the conductive band of perovskite relative to the highest occupied molecular orbital (HOMO) and lowest unoccupied molecular orbital (LUMO) of the neighboring hole (electron) transport layer determine if they are barrier-free for hole (electron) extraction while good blocking properties for electron (hole) extraction which affects electron-hole recombination at interfaces. Consequently, a comprehensive understanding of the electronic structure evolution caused by oxygen/water vapor-induced degradation processes is of paramount importance for improving perovskite device lifetime.

Photoelectron spectroscopy measure both the electronic structure and the chemical composition of a semiconductor. Particularly relevant energetic parameters are the work function, the ionization potential, and the energy difference between the valence band and the Fermi level. The triiodide $\mathrm{CH}_{3} \mathrm{NH}_{3} \mathrm{PbI}_{3}$ and mixed halide $\mathrm{CH}_{3} \mathrm{NH}_{3} \mathrm{PbI}_{3-\mathrm{x}} \mathrm{Cl}_{\mathrm{x}}$ are the common perovskite materials widely used as solar energy harvesters in the field of solar cells with high efficiency output. ${ }^{1,31-32}$ In this work, we systematically investigate the influence of environmental factors on the electronic structure of 
$\mathrm{CH}_{3} \mathrm{NH}_{3} \mathrm{PbI}_{3}$ and $\mathrm{CH}_{3} \mathrm{NH}_{3} \mathrm{PbI}_{3-\mathrm{x}} \mathrm{Cl}_{x}$ perovskite films by controlled oxygen and water vapor exposure, separately probed by ultraviolet photoelectron spectroscopy (UPS) in ultra-high vacuum (UHV). The UHV condition rules out the other effects from ambient air. The film composition, crystalline structure and surface morphology are monitored by a combination of X-ray photoelectron spectroscopy (XPS), X-ray diffraction (XRD) and scanning electron microscopy (SEM). The time-resolved photoluminescence (TRPL) is used to probe decay kinetics after degradation. Our in situ approach enables precise results on the electronic structure evolution of the typical solar cell perovskite materials in controlled time, which contributes in better understanding of the device degradation mechanisms, especially the physics mechanisms that cause the burn-in.

\section{Results and Discussion}

Figure 1a show UPS spectra of a typical $\mathrm{CH}_{3} \mathrm{NH}_{3} \mathrm{PbI}_{3}$ film as function of exposure time under the controlled oxygen gas at a pressure of $3 \times 10^{-5}$ mbar. The dose of gas exposure is estimated to be $22.5 \mathrm{~L} / \mathrm{s}$. The relationship betw een exposure dose and time is exhibited in Figure S1. The bottom spectrum corresponds to the pristine perovskite film. Its work function derived from the secondary electron cutoff and the position of valence band maximum (VBM) below Fermi level are estimated to be 5.06 and 0.94 $\mathrm{eV}$, respectively. The ionization potential defined as the energy difference between the vacuum level and the VBM is thus approximately $6.0 \mathrm{eV}$, consistent with previous reported values ${ }^{33}$. Upon increasing exposure time from 5 to $270 \mathrm{~min}$, an upward vacuum level shift of $0.22 \mathrm{eV}$ is observed as the work function increases to $5.28 \mathrm{eV}$, where it 
stabilizes after $90 \mathrm{~min}$. The VBM edge keeps a constant value of $0.94( \pm 0.02) \mathrm{eV}$ and the valence features are not affected by oxygen exposure. The ionization potential is thus raised from 6.0 to $6.22 \mathrm{eV}$. When the sample is stored in UHV without exposure for $12 \mathrm{~h}$ (see dash line in Figure 1a), the work function partially recovers and takes a value of $5.15 \mathrm{eV}$. The results and corresponding energy level diagrams are summarized in Figure 1b-c. Analogous results occur for the mixed-halide perovskite $\mathrm{CH}_{3} \mathrm{NH}_{3} \mathrm{PbI}_{3}$ ${ }_{\mathrm{x}} \mathrm{Cl}_{\mathrm{x}}$ as is shown in Figure S2. Initially, the films yield a work function of $4.75 \mathrm{eV}$ and an ionization potential of $5.86 \mathrm{eV}$ as the VBM is located at $1.10( \pm 0.02 \mathrm{eV})$ below the Femi level. When exposed to oxygen, the work function upshifts to $5.17 \mathrm{eV}$, showing a saturating trend, whereas the VMB remains fixed regardless of $\mathrm{O}_{2}$ exposure time. Hence, the work function and VBM differ between the two types of perovskite films, but their response to $\mathrm{O}_{2}$ exposure follows the same trend.

Figure 2a exhibits the UPS spectral evolution for a typical $\mathrm{CH}_{3} \mathrm{NH}_{3} \mathrm{PbI}_{3}$ film upon water vapor exposure at the pressure of $3 \times 10^{-5} \mathrm{mbar}$. With increasing water vapor time, the work function gradually decreases so that it reached $4.42 \mathrm{eV}$ after $1590 \mathrm{~min}$. At the same time, the VBM relative to the Fermi level shifts towards higher binding energy by $0.62 \mathrm{eV}$, from 0.96 to $1.58 \mathrm{eV}$, resulting in a nearly constant in IP of $6.0 \mathrm{eV}$ (Figure 2b). This indicates that at this stage water acts as an n-type dopant, given the charge transfer band gap of $1.7 \mathrm{eV}$ for the $\mathrm{CH}_{3} \mathrm{NH}_{3} \mathrm{PbI}_{3},{ }^{27}$ the shift puts the Fermi level very close to the bottom of the conduction band. It should be stressed that the valence spectral features stay unaltered, but the shifts in work function and VBM show no 
saturating trend. After storing the sample in UHV without exposure for $14.5 \mathrm{~h}$ (dash line in Figure 2a), the work function and the VMB increase to 4.55 and $1.45 \mathrm{eV}$, respectively, far from the values for pristine films. The corresponding energy level diagram is summarized in Figure 2c. A similar trend is obtained for $\mathrm{CH}_{3} \mathrm{NH}_{3} \mathrm{PbI}_{3-\mathrm{X}} \mathrm{Cl}_{\mathrm{x}}$ films when exposed to water vapor, shown in Figure S3. After exposure for $420 \mathrm{~min}$, the work function decreases by $0.57 \mathrm{eV}$ (from 4.72 to 4.15 ) and the VBM increases by roughly the same amount, $0.60 \mathrm{eV}$ (1.13 to 1.73$)$, so that the ionization potential stays constant. There is no saturating trend for work function and VBM shifts.

We summarize the UPS results for the effects of oxygen and water on the surface electronic structure in perovskite $\mathrm{CH}_{3} \mathrm{NH}_{3} \mathrm{PbI}_{3}$ and $\mathrm{CH}_{3} \mathrm{NH}_{3} \mathrm{PbI}_{3-\mathrm{x}} \mathrm{Cl}_{\mathrm{x}}$ films: (i) for oxygen exposure, the vacuum level of the perovskite film upshifts as the work function increases until the saturation status. The VBM stays at a constant versus Fermi level, resulting in the overall IP increase, see Figure 3a. (ii) For water vapor exposure, the vacuum level significantly downshifts as the work function deceases and the VMB referenced to Fermi level simultaneously increases so as to keep the ionization potential constant, see Figure 3b. This behavior shows no saturating trends for the exposure time used in the experiments.

To explore the origin of electronic structure evolution, XPS measurements were carried out to examine elemental changes before and after exposure, shown in Figure S4. The C1s core level of the $\mathrm{CH}_{3} \mathrm{NH}_{3} \mathrm{PbI}_{3}$ film contains two contributions, one at 
higher binding energy (286.5 eV) that represents the $\mathrm{C}-\mathrm{N}$ bond found in anion $\mathrm{CH}_{3} \mathrm{NH}_{3}^{-}$, and one at lower binding energy (285.1 eV, C-C, C-H) that typically is attributed to absorbed hydrocarbons resulting from ex-situ (and solution-based) preparation of the perovskite films. ${ }^{21,34}$ After oxygen exposure, there are no new features in the C1s, N1s, $\mathrm{Pb} 4 \mathrm{f}$ and I3d core level spectra, suggesting that the oxygen has negligible effect on the perovskite film chemical composition, see Figure S4a-e. The core level positions are nearly unaffected (within measurement error) by oxygen exposure, which suggested that the same size of shift for the work function and ionization potential is due to the formation of an oxygen-induced surface dipole. Our results further mean that the studied perovskite film is not very sensitive to oxygen, in agreement with the previous report. $^{35}$

For water exposure, there is no significant change in the core level spectral shape, but the perovskite element core levels undergo a rigid shift of $0.5 \mathrm{eV}$ to higher binding energy (Figure S4f-j). This shift is of the same size as the work function decrease and VMB increase versus Fermi level for this exposure time, suggesting band bending in the surface region through n-type doping by water. The XPS results further indicate that the perovskite films are chemically stable for a limited dose of water exposure. These results are further supported by the surface morphology analysis with SEM. Figure 4a shows topography images of the $\mathrm{CH}_{3} \mathrm{NH}_{3} \mathrm{PbI}_{3}$ before and after exposure. The pristine film is crystalline, uniform and compact, and the distribution of the grain size is homogeneous. After exposure to oxygen or water, there is no significant surface 
morphological change, further indicating that neither the oxygen nor water vapor damage to the perovskite film.

To provide additional insight, structure analysis using XRD is depicted in Figure 4b as well. The $\mathrm{CH}_{3} \mathrm{NH}_{3} \mathrm{PbI}_{3}$ film shows a tetragonal crystalline phase with XRD peaks at $14.1^{\circ}, 28.4^{\circ}$ and $43.2^{\circ}$ for the (110), (220) and (330), respectively, indicating that the pristine perovskite film has good purity and crystallinity in line with published results. ${ }^{21,36}$ However, after oxygen exposure, the weak peak at $12.5^{\circ}$ has emerged, pointing to an infinitesimal transformation from $\mathrm{CH}_{3} \mathrm{NH}_{3} \mathrm{PbI}_{3}$ to $\mathrm{PbI}_{2}$. Since the amount of $\mathrm{PbI}_{2}$ is too minute and the $\mathrm{Pb}^{2+}$ in $\mathrm{PbI}_{2}$ has the similar chemical environment with that of $\mathrm{CH}_{3} \mathrm{NH}_{3} \mathrm{PbI}_{3}$, the existence of $\mathrm{PbI}_{2}$ cannot be detected by SEM and XPS measurements, also they are only surface sensitive while XRD bulk technique. For water exposure, the perovskite-related peaks have no change and there is no additional peak appearing. These analogous results also occur in the perovskite $\mathrm{CH}_{3} \mathrm{NH}_{3} \mathrm{PbI}_{3-\mathrm{x}} \mathrm{Cl}_{\mathrm{x}}$ films (Figure S7). Hence, oxygen vapor does induce very minor yet non-negligible changes to the chemical composition of the perovskite films.

Next, we turn to the photoluminescent (PL) decay kinetics as provided in Figure 5. The PL intensity was normalized to the peak intensity for comparison. The PL dynamics of the pristine and the oxygen-exposed $\mathrm{CH}_{3} \mathrm{NH}_{3} \mathrm{PbI}_{3}$ film display the same slow and nearly monoexponential decay profile with a lifetime of 7.6 ns, which is comparable to the previous reports. ${ }^{37-38}$ In other words, the oxygen-exposed perovskite 
sample in UHV indeed does not significantly differ from the pristine (dry air exposed) perovskite sample in atmosphere, which suggests that oxygen molecules absorb on the film surface, as a result, that the oxygen induced very tiny amount of $\mathrm{PbI}_{2}$ formation does not significantly affect the electronic structure and the PL kinetic properties. However, when the films are exposed to water, a fast component appears with a short lifetime of $0.87 \mathrm{~ns}$, which is attributed to enhanced nonradiative charge recombination. The diminished PL lifetime in the water vapor exposed perovskite films possibly can be explained by the formation of the $\mathrm{CH}_{3} \mathrm{NH}_{3} \mathrm{PbI}_{3} \cdot \mathrm{H}_{2} \mathrm{O}$ complex or water molecule diffusing into a $\mathrm{CH}_{3} \mathrm{NH}_{3}{ }^{-}$site there acting as the charge trap. ${ }^{39}$

The $\mathrm{CH}_{3} \mathrm{NH}_{3} \mathrm{PbI}_{3-\mathrm{x}} \mathrm{Cl}_{\mathrm{x}}$ perovskite films have a more porous structure compared to $\mathrm{CH}_{3} \mathrm{NH}_{3} \mathrm{PbI}_{3}$ (see Figure S6), likely leading to $\mathrm{O}_{2}$ absorption at the grain boundaries in film as well as the surface, causing the observed decrease of PL life time shown in Figure S8. Water vapor exposure slightly alters the $\mathrm{CH}_{3} \mathrm{NH}_{3} \mathrm{PbI}_{3-\mathrm{x}} \mathrm{Cl}_{\mathrm{x}}$ perovskite film surface morphologies and smooths the gain boundary, which is accompanied by reduced PL life time, see Figure S8, in line with the appearance in the case of the $\mathrm{CH}_{3} \mathrm{NH}_{3} \mathrm{PbI}_{3}$ film, but a stronger effect as expected from the more porous film morphology.

\section{Conclusion}

In conclusion, we have investigated the effect of controlled in situ oxygen gas and water vapor exposure on the stability of $\mathrm{CH}_{3} \mathrm{NH}_{3} \mathrm{PbI}_{3}$ and $\mathrm{CH}_{3} \mathrm{NH}_{3} \mathrm{PbI}_{3-\mathrm{x}} \mathrm{Cl}_{\mathrm{x}}$ 
perovskite films from an electronic structural, chemical, morphological and dynamical point of view. We find that the evolution of their energy level diagrams follows the same trends for the two types of perovskite films. Oxygen gas exposure induces an upwards shift of the vacuum level of the perovskite films, i.e. a work function increase, due to the formation of an oxygen-induced surface dipole. The size of the work function shift saturates as expected for a surface dipole induced shift. The valence band features do not change, leading to the overall IP increase matching the increase of the work function. We additionally find that oxygen induces an infinitesimal transformation from the $\mathrm{CH}_{3} \mathrm{NH}_{3} \mathrm{PbI}_{3}$ to $\mathrm{PbI}_{2}$. The film morphology and the PL lifetime do not significantly change after oxygen exposure for the compact $\mathrm{CH}_{3} \mathrm{NH}_{3} \mathrm{PbI}_{3}$ films, whereas the more porous $\mathrm{CH}_{3} \mathrm{NH}_{3} \mathrm{PbI}_{3-\mathrm{x}} \mathrm{Cl}_{\mathrm{x}}$ films see a slight decrease in PL life time, attributed to oxygen absorption at grain boundaries in the bulk film. Water vapor affects the perovskite films differently than oxygen gas, in that the vacuum level significantly downshifts (work function deceases) and the valence band binding energy referenced to Fermi level simultaneously increase so as to keep the IP of the perovskite films unchanged. There was no saturating trend for the shifts for the exposure times used. This behavior suggests that the water molecules act as n-type dopants. The PL lifetime in the perovskite films dramatically reduces upon water exposure, attributed to the formation of the $\mathrm{CH}_{3} \mathrm{NH}_{3} \mathrm{PbI}_{3} \cdot \mathrm{H}_{2} \mathrm{O}$ complex or water molecule diffusing into the $\mathrm{CH}_{3} \mathrm{NH}_{3}{ }^{-}$site of the perovskite matrix acting as the charge trap center. These fast changes on energetics and dynamics might be related to the initial burn-in degradation of perovskite solar cells. These findings deliver the message that the encapsulation of 
the current popular perovskite-based devices is extremely important and of high requirement. Finally, we present energy level diagrams of perovskite films during degradation that provides guidance for further stable perovskite material and the related-device design.

\section{Experimental Section}

Perovskite Film Preparation: The $\mathrm{CH}_{3} \mathrm{NH}_{3} \mathrm{I}$ power was purchased from Dyesol. Ltd. The $\mathrm{PbI}_{2}$ and $\mathrm{PbCl}_{2}$ were obtained from TCI and Sigma, respectively. All the materials were used as received without purification. The $\mathrm{CH}_{3} \mathrm{NH}_{3} \mathrm{PbI}_{3}$ solution was mixed by $\mathrm{PbI}_{2}$ and $\mathrm{CH}_{3} \mathrm{NH}_{3} \mathrm{I}$ (1:1) in N, N-Dimethylformamide (DMF), and Dimethyl sulfoxide (DMSO) is added as additive. The $\mathrm{CH}_{3} \mathrm{NH}_{3} \mathrm{PbI}_{3-\mathrm{x}} \mathrm{Cl}_{\mathrm{x}}$ solution was prepared by mixing $\mathrm{CH}_{3} \mathrm{NH}_{3} \mathrm{I}$ and $\mathrm{PbCl}_{2}(1: 3)$ in DMF. All solutions were stirred at $60{ }^{\circ} \mathrm{C}$ for 3 hours and filtered before use. The $\mathrm{CH}_{3} \mathrm{NH}_{3} \mathrm{PbI}_{3}$ films was spin-coated on PEDOT: PSS in $\mathrm{N}_{2}$ glove box. During the spin coating process, $150 \mu \mathrm{L}$ toluene was quickly poured onto the film, and the films were annealed at $100^{\circ} \mathrm{C}$ for 10 minutes. The $\mathrm{CH}_{3} \mathrm{NH}_{3} \mathrm{PbI}_{3-\mathrm{x}} \mathrm{Cl}_{\mathrm{x}}$ film was spin-coated on the PEDOT: PSS substrates and then annealed at $100{ }^{\circ} \mathrm{C}$ for 30 minutes. The prepared film samples were then protected by nitrogen protection and covered with aluminum foil to shield from air/light, directly and quickly transferred into the load lock chamber. The XRD of the pristine and the degraded perovskite films were measured with a X'Pert PRO, PANalytical diffractometer using $\mathrm{Cu} \mathrm{K}_{\alpha}$ radiation. The morphology was investigated on LEO 1550 Gemini-SEM. 
Photoelectron spectroscopy: The Photoelectron spectroscopy measurements were carried out in an UHV surface analysis system including a load lock chamber (base pressure $\left.1 \times 10^{-7} \mathrm{mbar}\right)$, a preparation chamber ( $\left.8 \times 10^{-10} \mathrm{mbar}\right)$, and an analysis chamber (2 $\times 10^{-10}$ mbar). In situ exposure of the perovskite film to oxygen and water vapor respectively was carried in the preparation chamber under the pressure of $3 \times 10^{-5} \mathrm{mbar}$ controlled via a leak valve. After each exposure step, the film sample were transferred to the analysis chamber without breaking UHV for experiment. UPS and XPS spectra are recorded by Scienta-200 hemispherical analyzer. UPS was performed using HeI $21.22 \mathrm{eV}$ as excitation source to investigate the interfacial alignment and the frontier electronic structure features. The work function is derived from the secondary electron cut-off and the ionization potential from the frontier edge of the occupied density of states with energy resolution of $0.05 \mathrm{eV}$. XPS with monochromatized Al Ka $1486.6 \mathrm{eV}$ was detect possible chemical interaction after exposure. All measurements were calibrated by referencing to the Fermi level and $\mathrm{Au} 4 \mathrm{f}_{7 / 2}$ peak position of the $\mathrm{Ar}^{+}$ion sputter-clean gold foil. All exposure experiments and measurements were carried out in chambers shielded from the light and near-dark conditions.

Time-resolved photoluminescence: The TRPL measurements were performed in the ambient environment. A wavelength tunable Ti: Sapphire pulsed laser with a pulse repetition rate of $76 \mathrm{MHz}$ and spectral and temporal width of $10 \mathrm{~nm}$ and $150 \mathrm{fs}$, is used for excitation. The excitation wavelength of the laser is tuned to $400 \mathrm{~nm}$ and the laser beam is defocused to spot size with diameter of $1 \mathrm{~cm}$. The excitation density is fixed at 
$0.2 \mathrm{~W} / \mathrm{cm}^{2}$ for all measurements. The PL transients were detected by a streak camera assembled with a single grating monochromator.

\section{Acknowledgements}

The work is sponsored by the National Science Foundation of China grant No.11604099, the Fundamental Research Funds for the Central Universities, the Swedish Research Council project grant 2016-05498 and the Goran Gustafsson Foundation for Research in Nature Sciences and Medicine. X. L. and S. B. are grateful to support from the Swedish Government Strategic Research Area in Materials Science on Functional Materials at Linköping University (Faculty Grant SFO Mat LiU No 2009 00971), respectively. Z.Y. are grateful to the financial support from the China Scholarship Council. We thank Yuqing Huang (Division of Functional Electronic Materials, Linköping University) for the helpful discussion on TRPL data.

\section{Supporting Information}

Relationship between exposure dose and time, UPS energetics evolution of $\mathrm{CH}_{3} \mathrm{NH}_{3} \mathrm{PbI}_{3-\mathrm{x}} \mathrm{Cl}_{\mathrm{x}}$ as function of oxygen and water exposure time, XPS, SEM, XRD and TRPL of the pristine, oxygen and water exposed $\mathrm{CH}_{3} \mathrm{NH}_{3} \mathrm{PbI}_{3-\mathrm{x}} \mathrm{Cl}_{\mathrm{x}}$ films

\section{Author Information}

*Email: qybao@clpm.ecnu.edu.cn

The authors declare no competing financial interest. 


\section{References}

(1). Liu, M. Z;; Johnston, M. B.; Snaith, H. J., Efficient Planar Heterojunction Perovskite Solar Cells by Vapour Deposition. Nature 2013, 501, 395-398.

(2). Liu, D. Y.; Kelly, T. L., Perovskite Solar Cells with a Planar Heterojunction Structure Prepared Using Room-Temperature Solution Processing Techniques. Nat. Photonics 2014, 8, 133-138.

(3). Green, M. A.; Ho-Baillie, A.; Snaith, H. J., The Emergence of Perovskite Solar Cells. Nat. Photonics 2014, 8, 506-514.

(4). Chen, H.; Ye, F.; Tang, W. T.; He, J. J.; Yin, M. S.; Wang, Y. B.; Xie, F. X.; Bi, E. B.; Yang, X. D.; Gratzel, M.; Han, L. Y., A Solvent- and Vacuum-free Route to Large-area Perovskite Films for Efficient Solar Modules. Nature 2017, 550, 92-95.

(5). Jeon, N. J.; Noh, J. H.; Yang, W. S.; Kim, Y. C.; Ryu, S.; Seo, J.; Seok, S. I., Compositional Engineering of Perovskite Materials for High-Performance Solar Cells. Nature 2015, 517, 476-480.

(6). Albrecht, S.; Rech, B., On Top of Commercial Photovoltaics. Nat. Energy 2017, 2, 16196.

(7). Stranks, S. D.; Eperon, G. E.; Grancini, G.; Menelaou, C.; Alcocer, M. J. P.; Leijtens, T.; Herz, L. M.; Petrozza, A.; Snaith, H. J., Electron-Hole Diffusion Lengths Exceeding 1 Micrometer in an Organometal Trihalide Perovskite Absorber.Science 2013, 342, 341-344.

(8). Park, N.-G., Organometal Perovskite Light Absorbers Toward a 20\% Efficiency Low-Cost SolidState Mesoscopic Solar Cell.J. Phys. Chem. Lett. 2013, 4, 2423-2429.

(9). Brenner, T. M.; Egger, D. A.; Kronik, L.; Hodes, G.; Cahen, D., Hybrid Organic-Inorganic Perovskites: Low-Cost Semiconductors with Intriguing Charge-Transport Properties. Nat. Rev. Mater. 2016, 1, 15007.

(10). Yang, W. S.; Park, B. W.; Jung, E. H.; Jeon, N. J.; Kim, Y. C.; Lee, D. U.; Shin, S. S.; Seo, J.; Kim, E. K.; Noh, J. H.; Seok, S. I., lodide Management in Formamidinium-Lead-Halide-based Perovskite Layers for Efficient Solar Cells.Science 2017, 356, 1376.

(11). Saliba, M.; Matsui, T.; Seo, J. Y.; Domanski, K.; Correa-Baena, J. P.; Nazeeruddin, M. K.; Zakeeruddin, S. M.; Tress, W.; Abate, A.; Hagfeldt, A.; Gratzel, M., Cesium-containing Triple Cation Perovskite Solar Cells: Improved Stability, Reproducibility and High Efficiency. Energ. Environ. Sci. 2016, 9, 1989-1997.

(12). Gratzel, M., The Rise of Highly Efficient and Stable Perovskite Solar Cells.Acc. Chem. Res. 2017, 50, 487-491.

(13). Zhang, F.; Wang, Z.; Zhu, H.; Pellet, N.; Luo, J.; Yi, C.; Liu, X.; Liu, H.; Wang, S.; Li, X.; Xiao, Y.; Zakeeruddin, S. M.; Bi, D.; Grätzel, M., Over 20\% PCE Perovskite Solar Cells with Superior Stability Achieved by Novel and Low-cost Hole-transporting Materials. Nano Energy 2017, 41, 469-475.

(14). Konstantakou, M.; Stergiopoulos, T., A Critical Review on Tin Halide Perovskite Solar Cells.J. Mater. Chem. A 2017, 5, 11518-11549.

(15). Berhe, T. A.; Su, W. N.; Chen, C. H.; Pan, C. J.; Cheng, J. H.; Chen, H. M.; Tsai, M. C.; Chen, L. Y.; Dubale, A. A.; Hwang, B. J., Organometal Halide Perovskite Solar Cells: Degradation and Stability. Energ. Environ. Sci. 2016, 9, 323-356.

(16). Guerrero, A.; You, J. B.; Aranda, C.; Kang, Y. S.; Garcia-Belrnonte, G.; Zhou, H. P.; Bisquert, J.; Yang, Y., Interfacial Degradation of Planar Lead Halide Perovskite Solar Cells.Acs Nano 2016, 10, 218-224. 
(17). You, J. B.; Meng, L.; Song, T. B.; Guo, T. F.; Yang, Y.; Chang, W. H.; Hong, Z. R.; Chen, H. J.; Zhou, H. P.; Chen, Q.; Liu, Y. S.; De Marco, N.; Yang, Y., Improved Air Stability of Perovskite Solar Cells via Solution-processed Metal Oxide Transport Layers. Nat. Nanotechnol. 2016, 11, 75-81.

(18). Divitini, G.; Cacovich, S.; Matteocci, F.; Cina, L.; Di Carlo, A.; Ducati, C., In Situ Observation of Heat-induced Degradation of Perovskite Solar Cells.Nat. Energy 2016, 1, 15012.

(19). Domanski, K.; Alharbi, E. A.; Hagfeldt, A.; Grätzel, M.; Tress, W., Systematic investigation of the impact of operation conditions on the degradation behaviour of perovskite solar cells. Nat Energy 2018, 3, 61-67.

(20). Wang, Z.; McMeekin, D. P.; Sakai, N.; van Reenen, S.; Wojciechowski, K.; Patel, J. B.; Johnston, M. B.; Snaith, H. J., Efficient and Air-Stable Mixed-Cation Lead Mixed-Halide Perovskite Solar Cells with n-Doped Organic Electron Extraction Layers.Adv Mater 2017, 29, 1604186.

(21). Conings, B.; Drijkoningen, J.; Gauquelin, N.; Babayigit, A.; D'Haen, J.; D'Olieslaeger, L.; Ethirajan A.; Verbeeck, J.; Manca, J.; Mosconi, E.; De Angelis, F.; Boyen, H. G., Intrinsic Thermal Instability of Methylammonium Lead Trihalide Perovskite.Adv. Energy. Mater. 2015, 5, 1500477.

(22). Aristidou, N.; Eames, C.; Sanchez-Molina, I.; Bu, X. N.; Kosco, J.; Islam, M. S.; Haque, S. A., Fast Oxygen Diffusion and lodide Defects Mediate Oxygen-induced Degradation of Perovskite Solar Cells. Nat. Commun. 2017, 8, 15218.

(23). Li, Y. Z.; Xu, X. R.; Wang, C. C.; Ecker, B.; Yang, J. L.; Huang, J.; Gao, Y. L., Light-Induced Degradation of $\mathrm{CH}_{3} \mathrm{NH}_{3} \mathrm{Pbl}_{3}$ Hybrid Perovskite Thin Film.J. Phys. Chem. C 2017, 121, 3904-3910.

(24). Wang, C. C.; Li, Y. Z.; Xu, X. M.; Ecker, B.; Wang, C. G.; Gao, Y. L., Degradation of Co-Evaporated Perovskite Thin Films.MRS Adv. 2016, 1, 923-929.

(25). Schulz, P.; Edri, E.; Kirmayer, S.; Hodes, G.; Cahen, D.; Kahn, A., Interface Energetics in Organometal Halide Perovskite-based Photovoltaic Cells.Energ. Environ. Sci. 2014, 7, 1377-1381.

(26). Lo, M. F.; Guan, Z. Q.; Ng, T. W.; Chan, C. Y.; Lee, C. S., Electronic Structures and Photoconversion Mechanism in Perovskite/Fullerene Heterojunctions. Adv. Funct. Mater. 2015, 25 , 1213-1218

(27). Li, C.; Wei, J.; Sato, M.; Koike, H.; Xie, Z. Z.; Li, Y. Q.; Kanai, K.; Kera, S.; Ueno, N.; Tang, J. X., Halide-Substituted Electronic Properties of Organometal Halide Perovskite Films: Direct and Inverse Photoemission Studies.Acs Appl. Mater. Inter. 2016, 8, 11526-11531.

(28). Butler, K. T.; Frost, J. M.; Walsh, A., Band Alignment of the Hybrid Halide Perovskites $\mathrm{CH}_{3} \mathrm{NH}_{3} \mathrm{PbCl}_{3}, \mathrm{CH}_{3} \mathrm{NH}_{3} \mathrm{PbBr}_{3}$ and $\mathrm{CH}_{3} \mathrm{NH}_{3} \mathrm{Pbl}_{3}$. Mater. Horiz. 2015, 2, 228-231.

(29). Wang, R.; Wu, C.; Hu, Y.; Li, J.; Shen, P.; Wang, Q.; Liao, L.; Liu, L.; Duhm, S., CH3NH3Pbl3-xClx under Different Fabrication Strategies: Electronic Structures and Energy-Level Alignment with an Organic Hole Transport Material.Acs Appl. Mater. Inter. 2017, 9, 7859-7865.

(30). Haque, M. A.; Sheikh, A. D.; Guan, X. W.; Wu, T., Metal Oxides as Efficient Charge Transporters in Perovskite Solar Cells.Adv Energy Mater 2017, 7, 1602803.

(31). Shao, Y. H.; Xiao, Z. G.; Bi, C.; Yuan, Y. B.; Huang, J. S., Origin and Elimination of Photocurrent Hysteresis by Fullerene Passivation in $\mathrm{CH}_{3} \mathrm{NH}_{3} \mathrm{Pbl}_{3}$ Planar Heterojunction Solar Cells. Nat. Commun. 2014, 5, 5784.

(32). Gratzel, M., The light and Shade of Perovskite Solar Cells. Nat. Mater. 2014, 13, 838-842.

(33). Ou, Q. D.; Li, C.; Wang, Q. K.; Li, Y. Q.; Tang, J. X., Recent Advances in Energetics of Metal Halide Perovskite Interfaces.Adv. Mater. Interfaces 2017, 4, 1600694. 
(34). Chen, S.; Goh, T. W.; Sabba, D.; Chua, J.; Mathews, N.; Huan, C. H. A.; Sum, T. C., Energy Level Alignment at the Methylammonium Lead lodide/Copper Phthalocyanine Interface.Apl. Mater. 2014, 2, 081512

(35). Li, Y.; Xu, X.; Wang, C.; Wang, C.; Xie, F.; Yang, J.; Gao, Y., Degradation by Exposure of Coevaporated CH3NH3Pbl3 Thin Films.J. Phys. Chem. C 2015, 119, 23996-24002.

(36). Chaudhary, D. K.; Kumar, P.; Kumar, L., Impact of $\mathrm{CH}_{3} \mathrm{NH}_{3} \mathrm{Pbl}_{3}-\mathrm{PCBM}$ Bulk Heterojunction Active Layer on the Photovoltaic Performance of Perovskite Solar Cells. Chem. Phys. Lett. 2017, 685, 210-216.

(37). Wang, C.; Hao, H.; Chen, S.; Cao, K.; Yu, H.; Zhang, Q.; Wan, G.; Shang, W.; Huang, W., InverseArchitecture Perovskite Solar Cells with 5,6,11,12-tetraphenylnaphthacene as a Hole Conductor.RSC AdV. 2017, 7, 29944-29952.

(38). Li, C.; Wang, F. Z.; Xu, J.; Yao, J. X.; Zhang, B.; Zhang, C. F.; Xiao, M.; Dai, S. Y.; Li, Y. F.; Tan, Z. A., Efficient Perovskite/Fullerene Planar Heterojunction Solar Cells with Enhanced Charge Extraction and Suppressed Charge Recombination. Nanoscale 2015, 7, 9771-9778.

(39). Leguy, A. M. A.; Hu, Y.; Campoy-Quiles, M.; Alonso, M. I.; Weber, O. J.; Azarhoosh, P.; van Schilfgaarde, M.; Weller, M. T.; Bein, T.; Nelson, J.; Docampo, P.; Barnes, P. R. F., Reversible Hydration of $\mathrm{CH}_{3} \mathrm{NH}_{3} \mathrm{Pbl}_{3}$ in Films, Single Crystals, and Solar Cells. Chem. Mater. 2015, 27, 33973407. 
a.

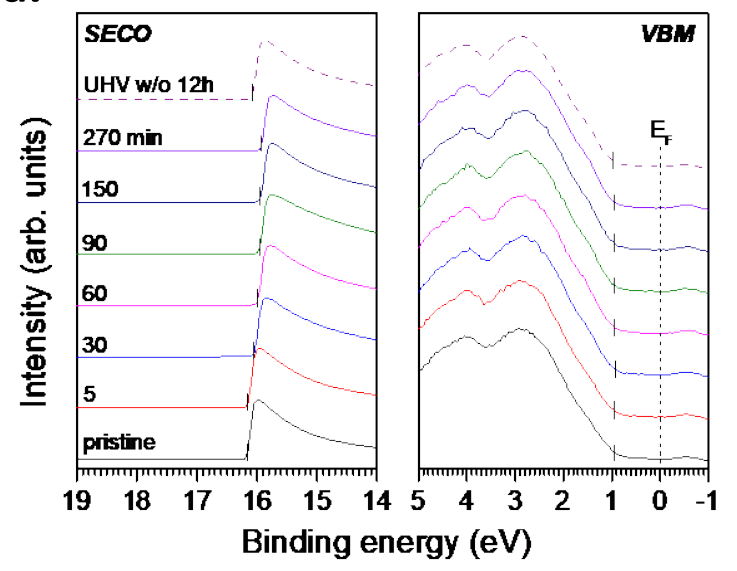

b.

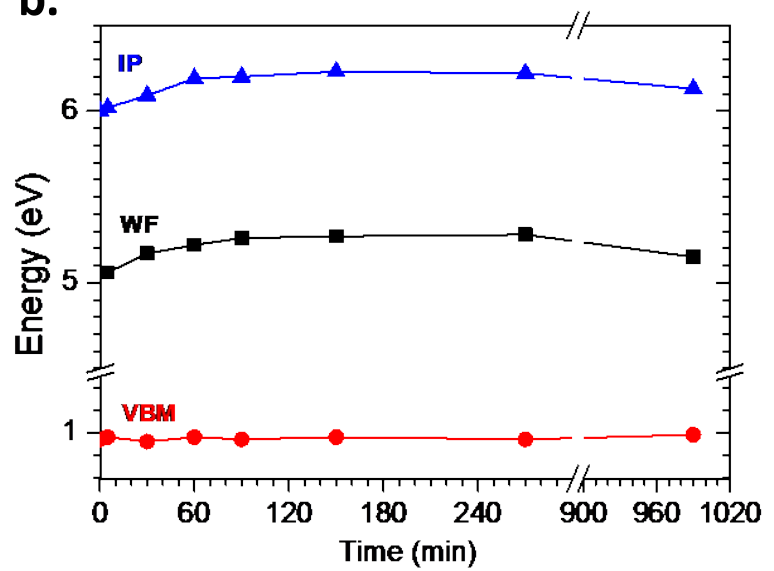

C.
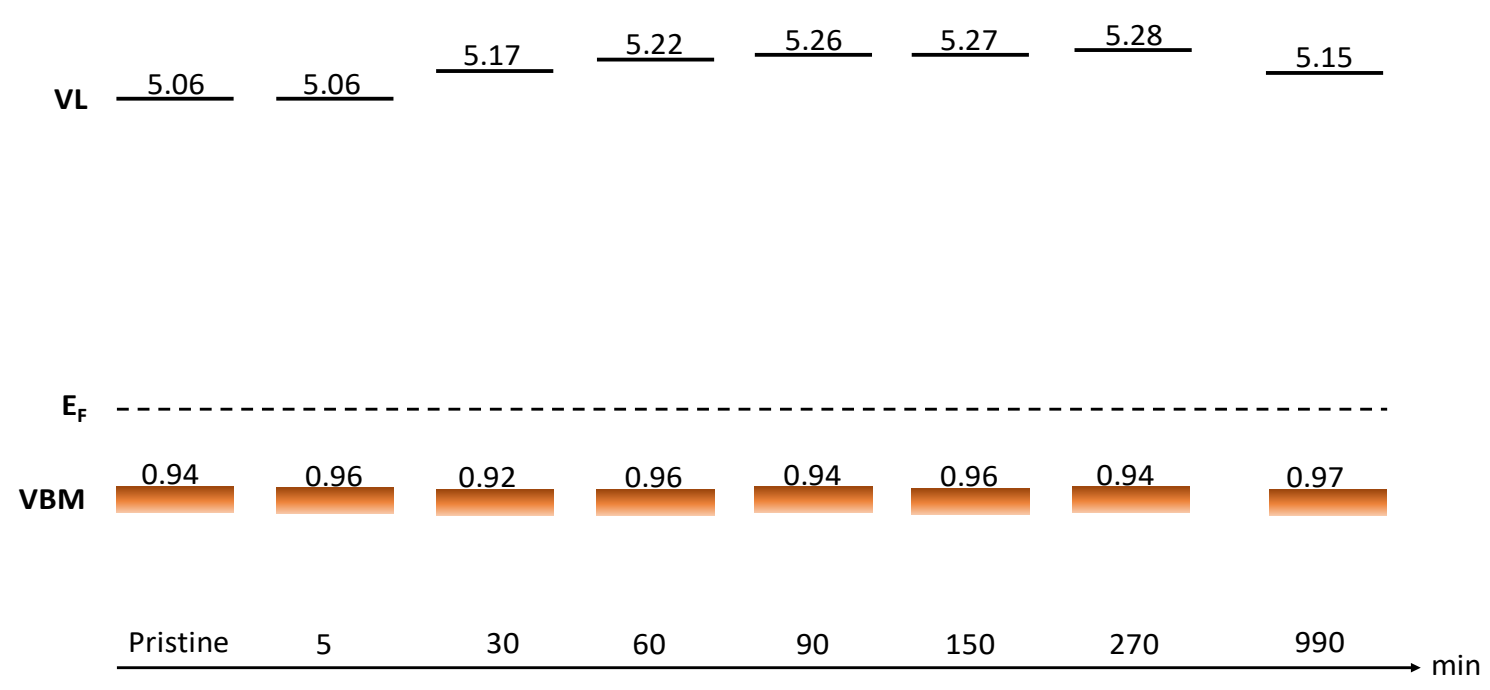

Figure 1. (a) UPS spectra in the secondary electron region and the frontier electronic structure region of the $\mathrm{CH}_{3} \mathrm{NH}_{3} \mathrm{PbI}_{3}$ film as function of in suit exposure time under the controlled oxygen gas at a pressure of $3 \times 10^{-5}$ mbar versus a base UHV of $1 \times 10^{-9} \mathrm{mbar}$; (b) Summary of work function (WF), valence band maximum (VBM) energy and ionization potential (IP). (c) Energy level diagrams of oxygen-exposed $\mathrm{CH}_{3} \mathrm{NH}_{3} \mathrm{PbI}_{3}$ films. The zero-binding energy is referred to $E_{F}$. The secondary electron cutoff (SECO) and the VBM respectively are shown in the UPS spectra. 


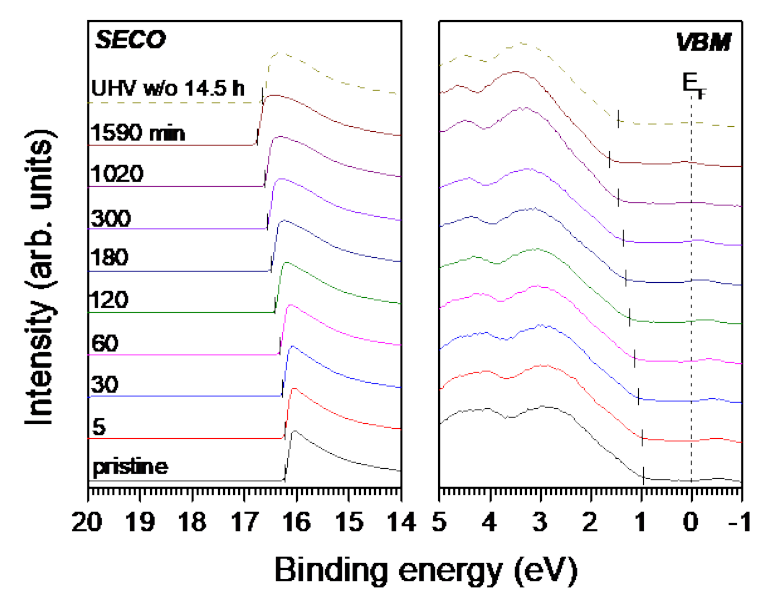

C.

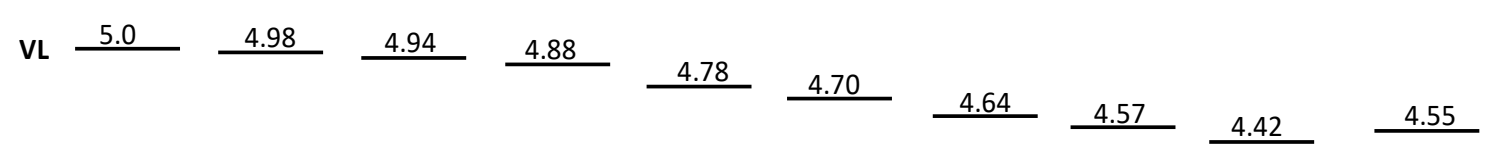

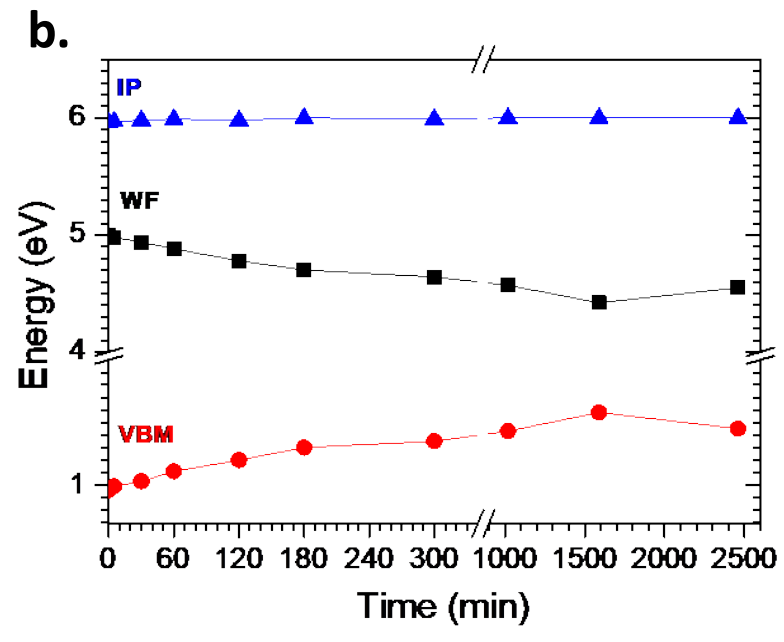

Figure 2. (a) UPS spectra in the secondary electron region and the frontier electronic structure region of the $\mathrm{CH}_{3} \mathrm{NH}_{3} \mathrm{PbI}_{3}$ film as function of in suit water exposure time at a pressure of $3 \times 10^{-5}$ mbar versus a base UHV of $1 \times 10^{-9}$ mbar; (b) Summary of WF, VBM energy and IP. (c) Energy level diagrams of water-exposed $\mathrm{CH}_{3} \mathrm{NH}_{3} \mathrm{PbI}_{3}$ films. 
a.

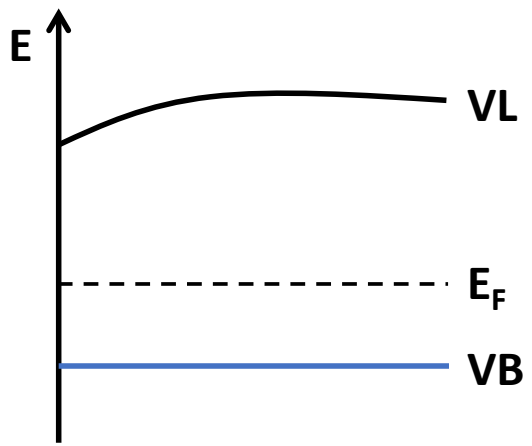

Exposure time b.

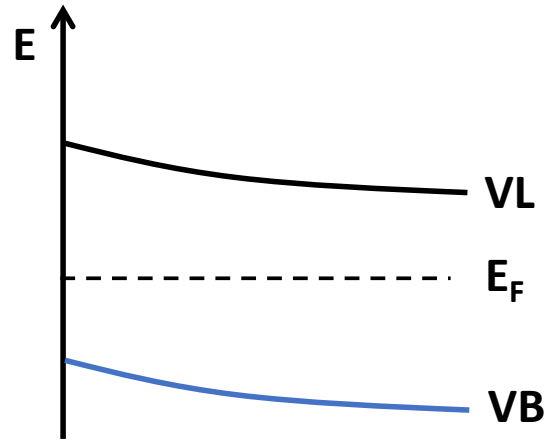

Exposure time

Figure 3. Electronic band structures determined for the $\mathrm{CH}_{3} \mathrm{NH}_{3} \mathrm{PbI}_{3}$ and $\mathrm{CH}_{3} \mathrm{NH}_{3} \mathrm{PbI}_{3-\mathrm{x}} \mathrm{Cl}_{\mathrm{x}}$ films as result of (a) oxygen and (b) water exposure 


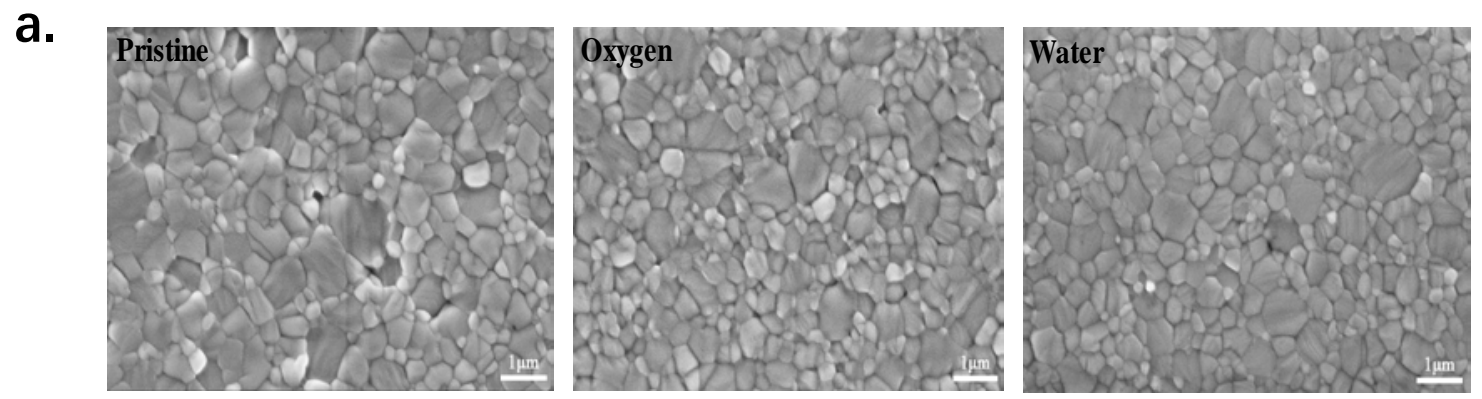

b.

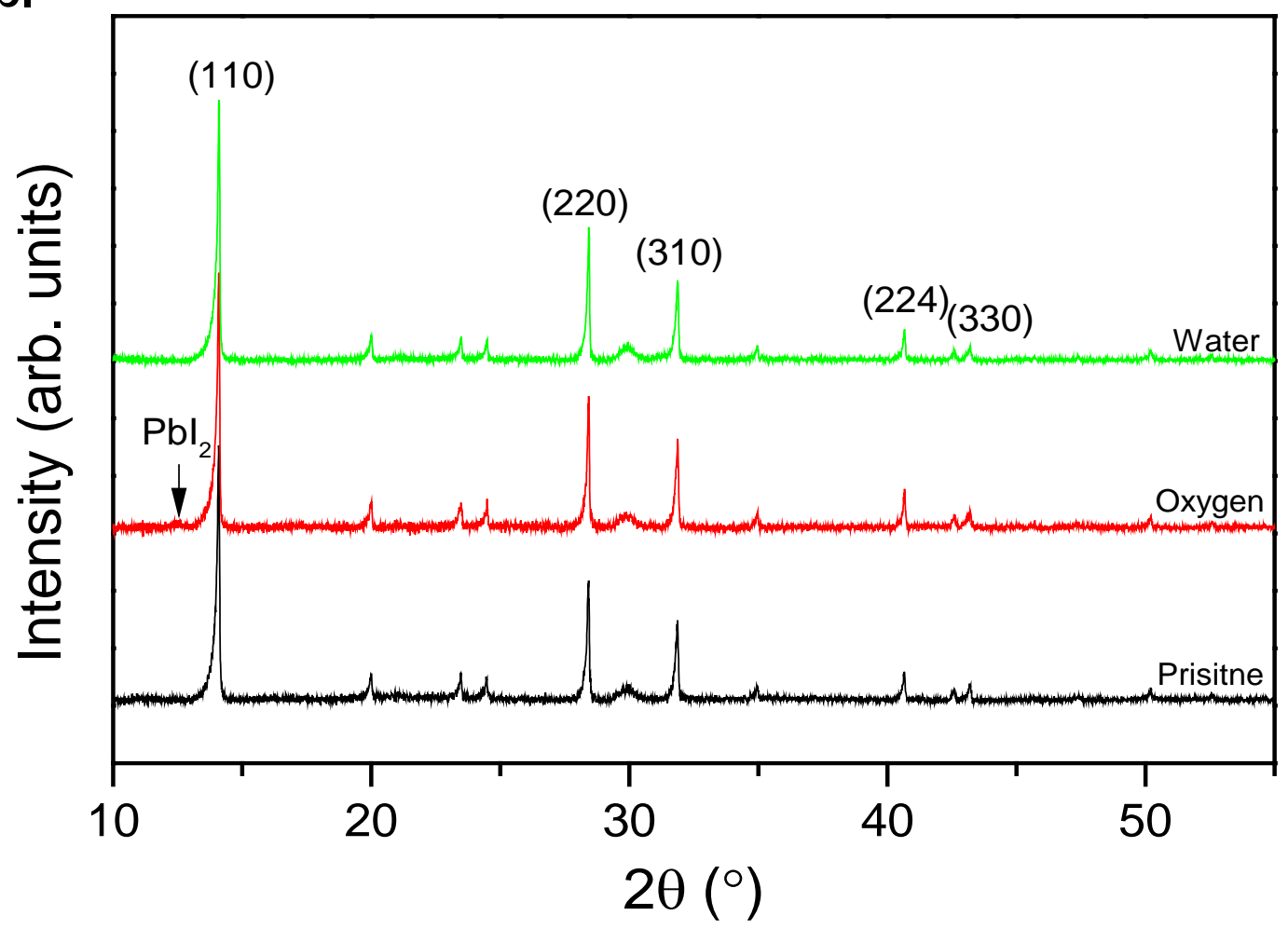

Figure 4. (a) Scanning electron microscopy images of the pristine, oxygen- and waterexposed perovskite films; (b) corresponding X-ray diffractograms 


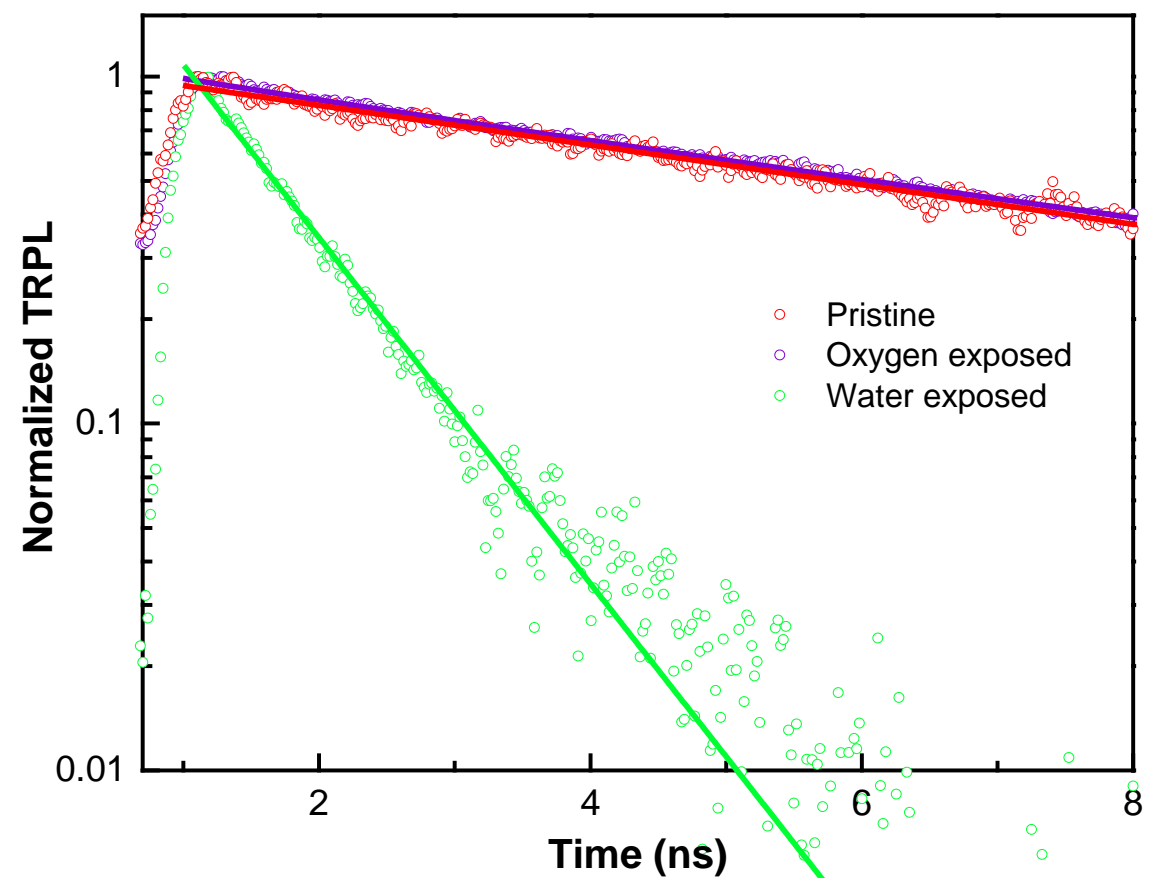

Figure 5. Photoluminescence decay kinetics of the $\mathrm{CH}_{3} \mathrm{NH}_{3} \mathrm{PbI}_{3}$ films before (red symbols) and after exposure (oxygen: violet symbols, water: green symbols). 
TOC

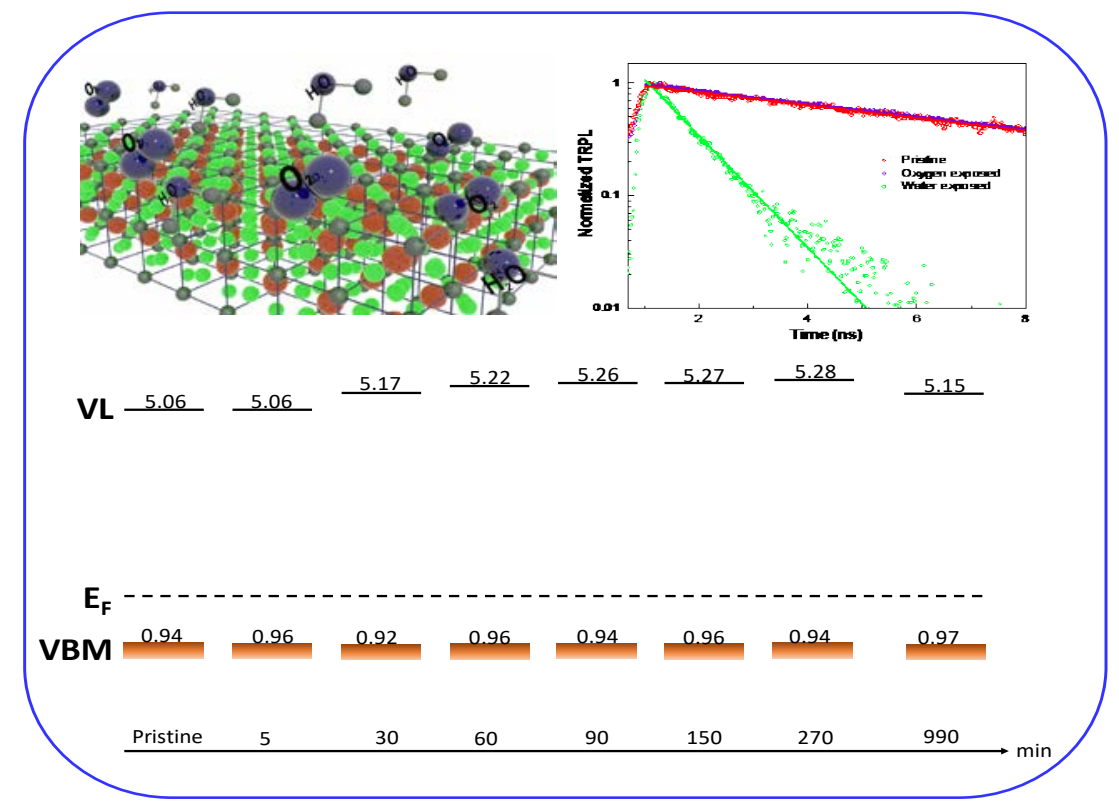




\section{Supporting Information}

\section{Oxygen- and Water-induced Energetics Degradation in Organometal Halide Perovskites}

Jianming Yang ${ }^{1, \#}$ Zhongcheng Yuan ${ }^{2},{ }^{\#}$ Xianjie Liu ${ }^{3}$, Slawomir Braun ${ }^{3}$, Yanqing $\mathrm{Li}^{4}$, Jianxin Tang ${ }^{4}$, Feng Gao $^{2}$, Chungang Duan ${ }^{1,5}$, Mats Fahlman ${ }^{3}$, Qinye Bao ${ }^{1,2^{*}}$

1 Key Laboratory of Polar Materials and Devices, Ministry of Education, East China Normal University, 200241, Shanghai, P.R. China

E-mail: qybao@clpm.ecnu.edu.cn

2 Division of Biomolecular and Organic Electronics, IFM, Linköping University SE58183 Linköping, Sweden

3 Division of Surface Physics and Chemistry, IFM, Linköping University SE-58183 Linköping, Sweden

4 Institute of Functional Nano \& Soft Materials (FUNSOM), Soochow University, Suzhou 215123, P. R. China

5 Collaborative Innovation Center of Extreme Optics, Shanxi University, Taiyuan, Shanxi, 030006, P.R. China

\# The authors contributed equally to this work.

Keywords: organometal halide perovskites; energetics; oxygen/water; degradation; perovskite solar cell 


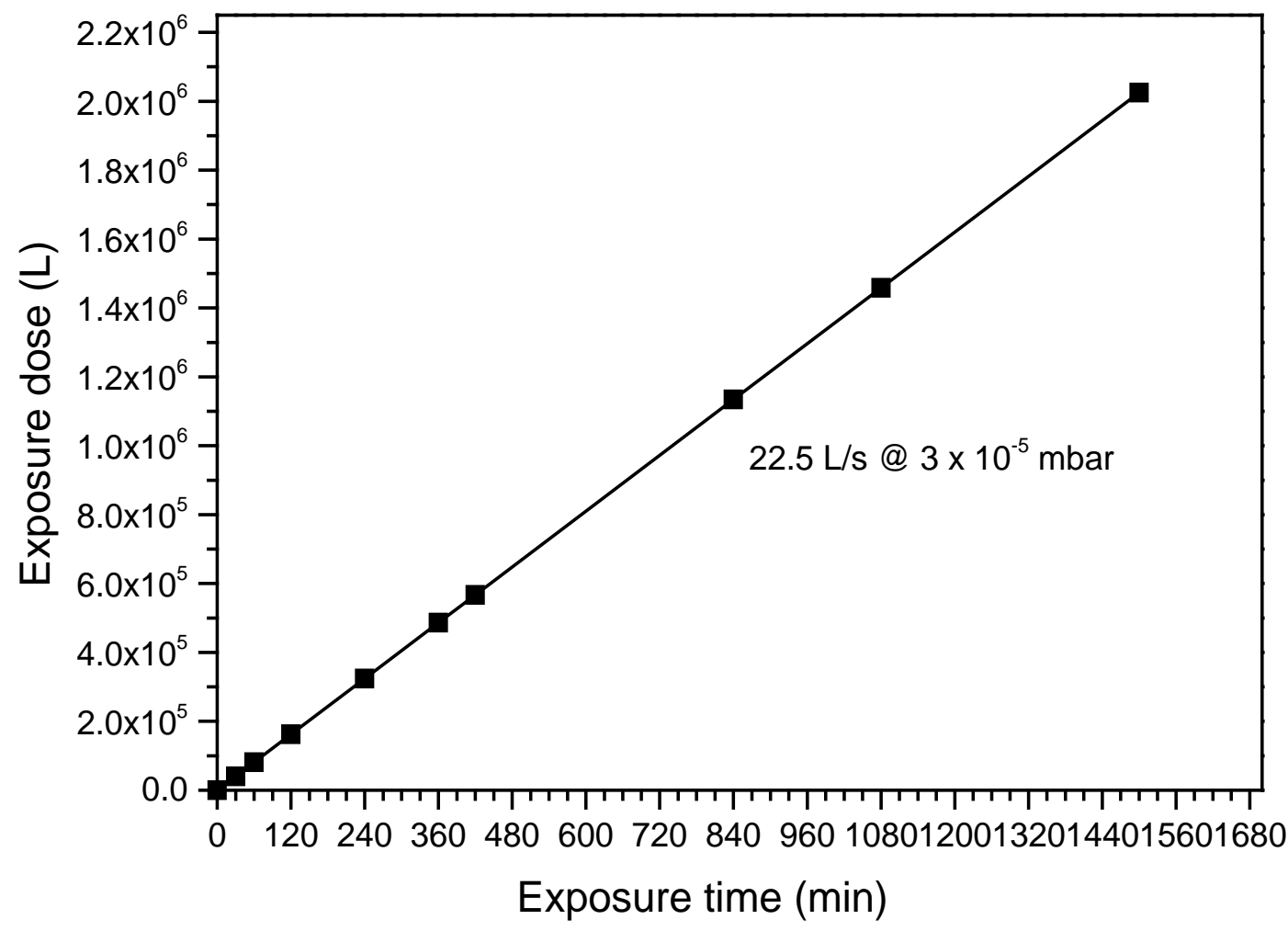

Figure S1. Relationship between exposure dose and exposure time at a pressure of $3 \mathrm{x}$ $10^{-5}$ mbar. Langmuir (L) is a unit of gas adsorption to a surface in ultrahigh vacuum (UHV), which is defined by multiplying the pressure of the gas by the time of gas exposure. $1 \mathrm{~L}$ corresponds to an exposure of $10^{-6}$ Torr $(\mathrm{T})$ during one second (s) ${ }^{1}$. In the experiment, the exposure pressure is $2.25 \times 10^{-5} \mathrm{~T}$ ( $3 \times 10^{-5}$ mbar), which means 22.5 L/s during exposure. 
a.

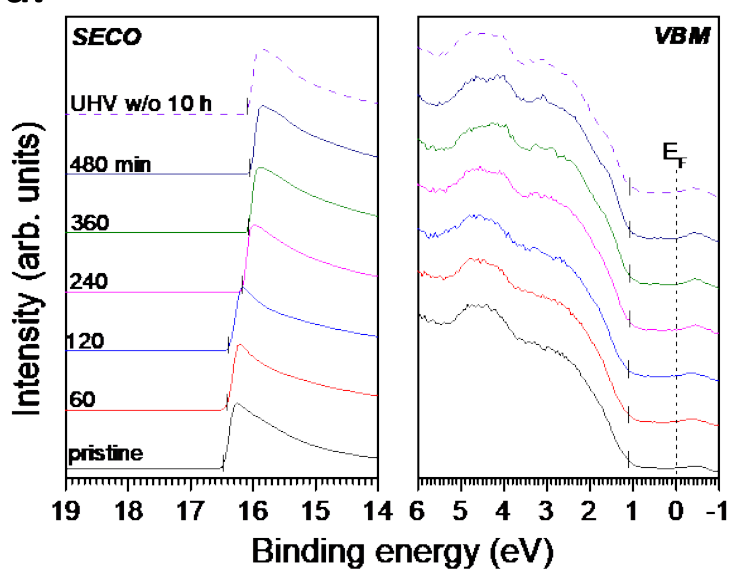

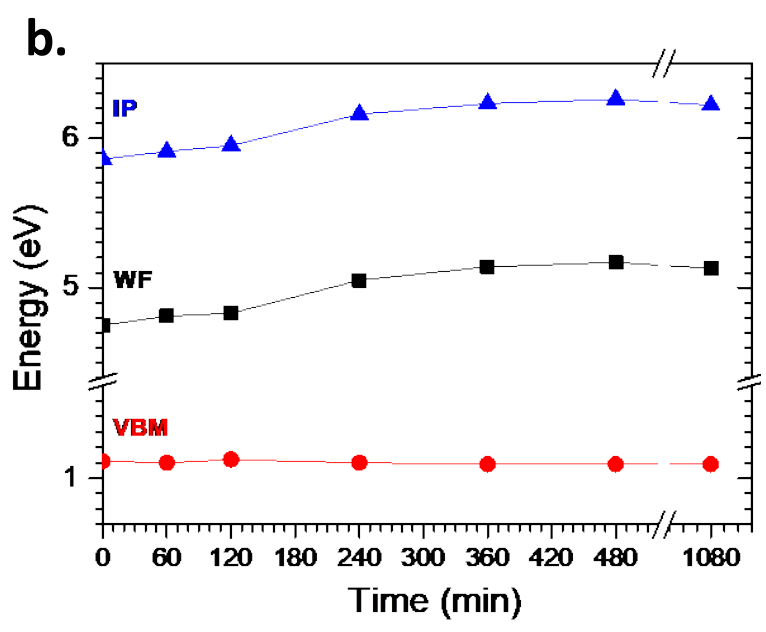

c.
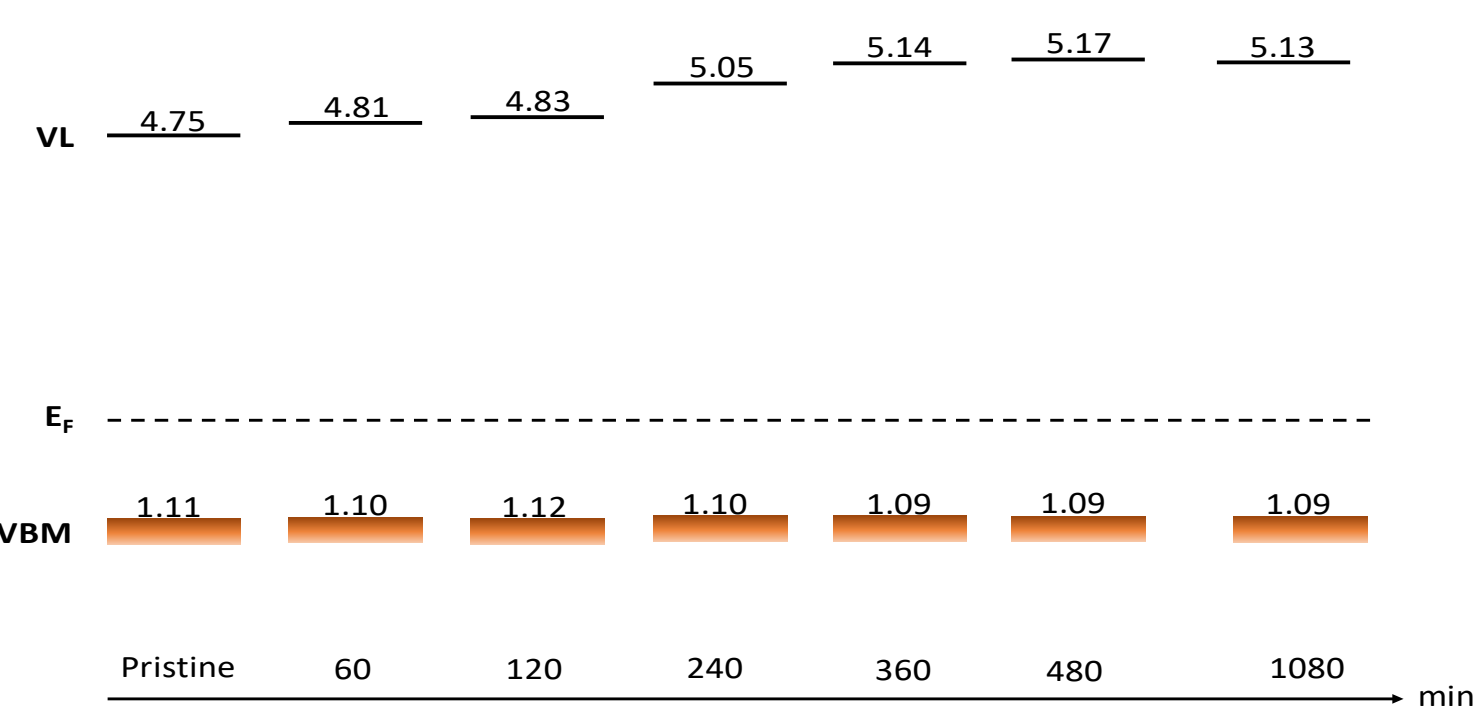

Figure S2. (a) UPS spectra in the secondary electron region and the frontier electronic structure region of the film as function of in suit oxygen exposure time under the pressure of $3 \times 10^{-5}$ mbar; (b) Summary of WF, VBM energy and IP. (c) Energy level diagrams of the oxygen-exposed $\mathrm{CH}_{3} \mathrm{NH}_{3} \mathrm{PbI}_{3-\mathrm{x}} \mathrm{Cl}_{\mathrm{x}}$ films. 
a.

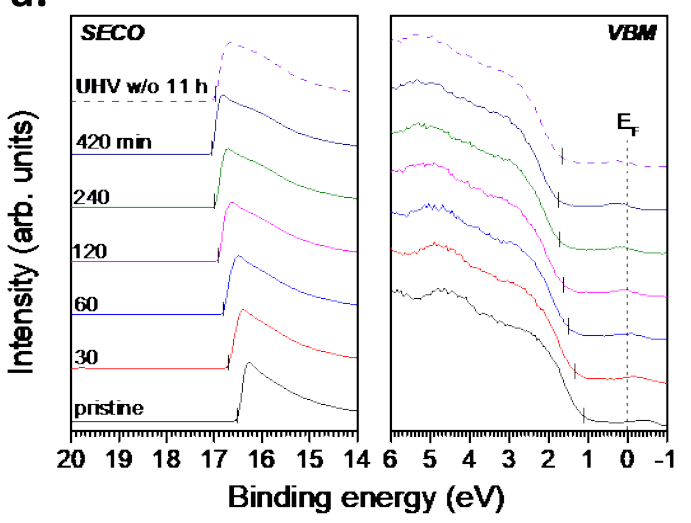

b.

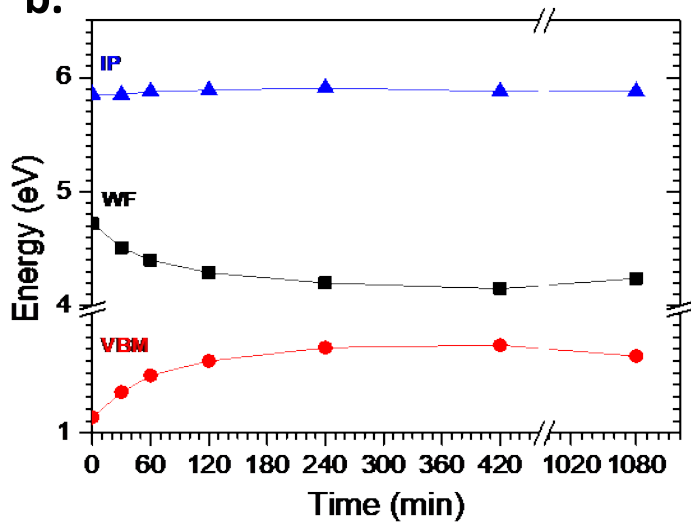

c.

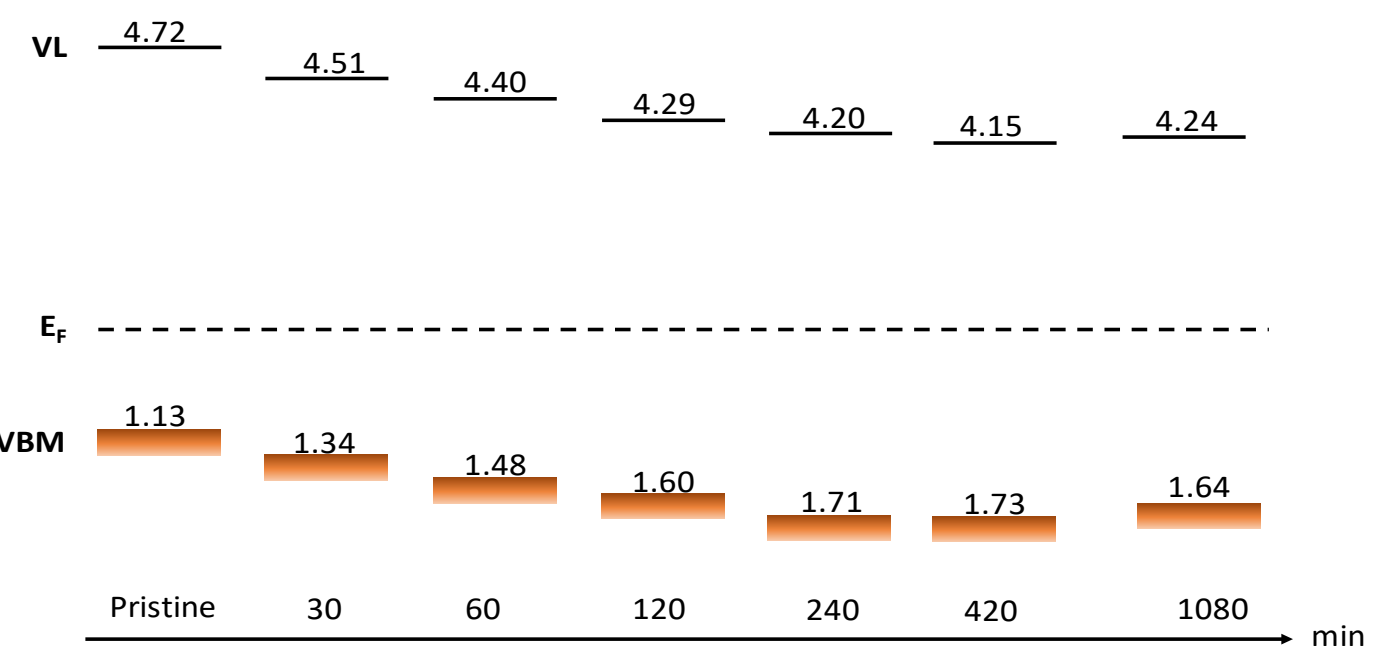

Figure S3. (a) UPS spectra in the secondary electron region and the frontier electronic structure region of the $\mathrm{CH}_{3} \mathrm{NH}_{3} \mathrm{PbI}_{3-\mathrm{x}} \mathrm{Cl}_{\mathrm{x}}$ film as function of in suit water exposure time under the pressure of $3 \times 10^{-5}$ mbar; (b) Summary of WF, VBM energy and IP. (c) Energy level diagrams of the water-exposed $\mathrm{CH}_{3} \mathrm{NH}_{3} \mathrm{PbI}_{3-\mathrm{x}} \mathrm{Cl}_{\mathrm{x}}$ films. 

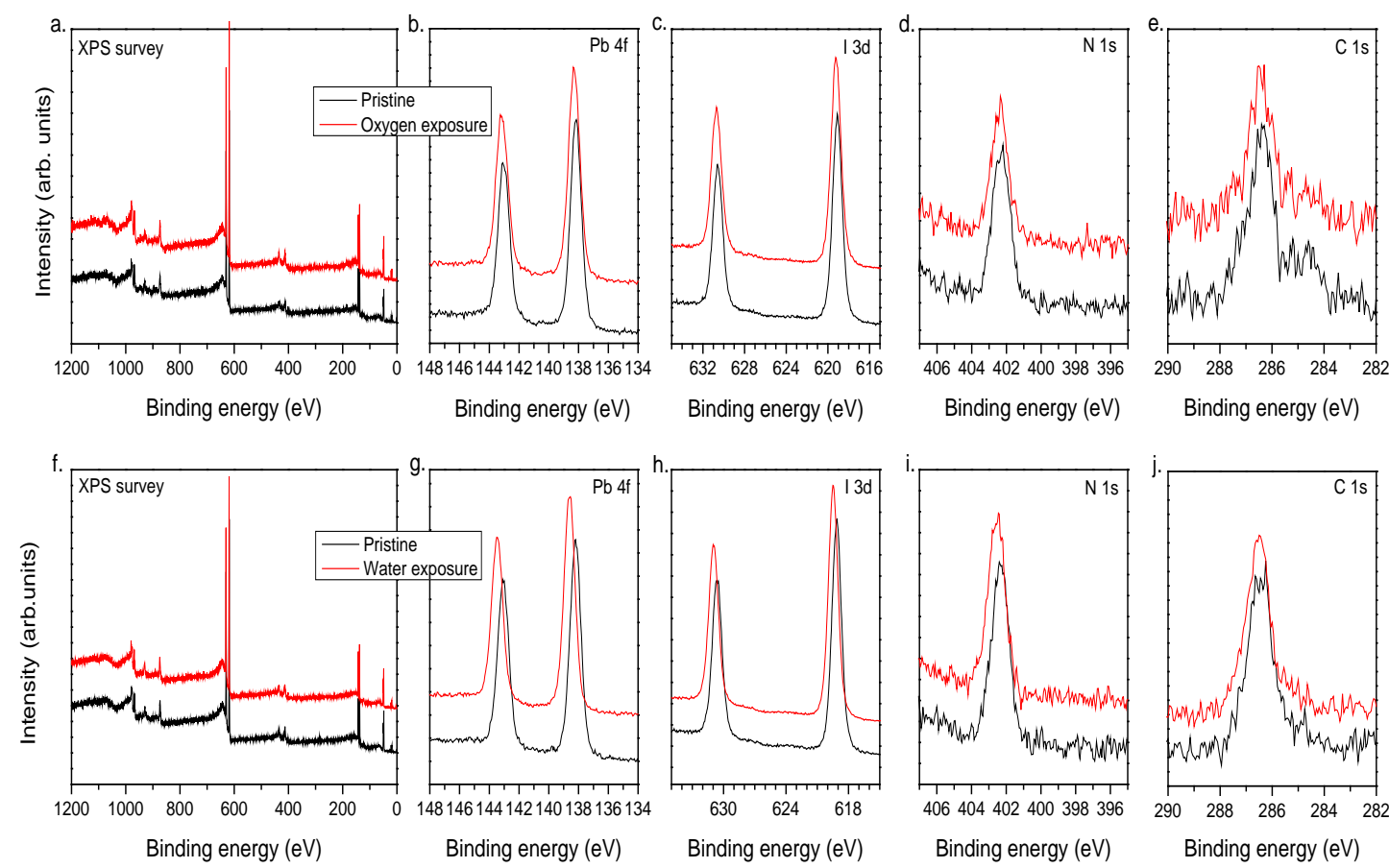

Figure S4. XPS survey spectra and Pb4f, I3d, N1s and C1s core level spectra of the $\mathrm{CH}_{3} \mathrm{NH}_{3} \mathrm{PbI}_{3}$ films before and after (a-e) oxygen and (f-j) water exposure 

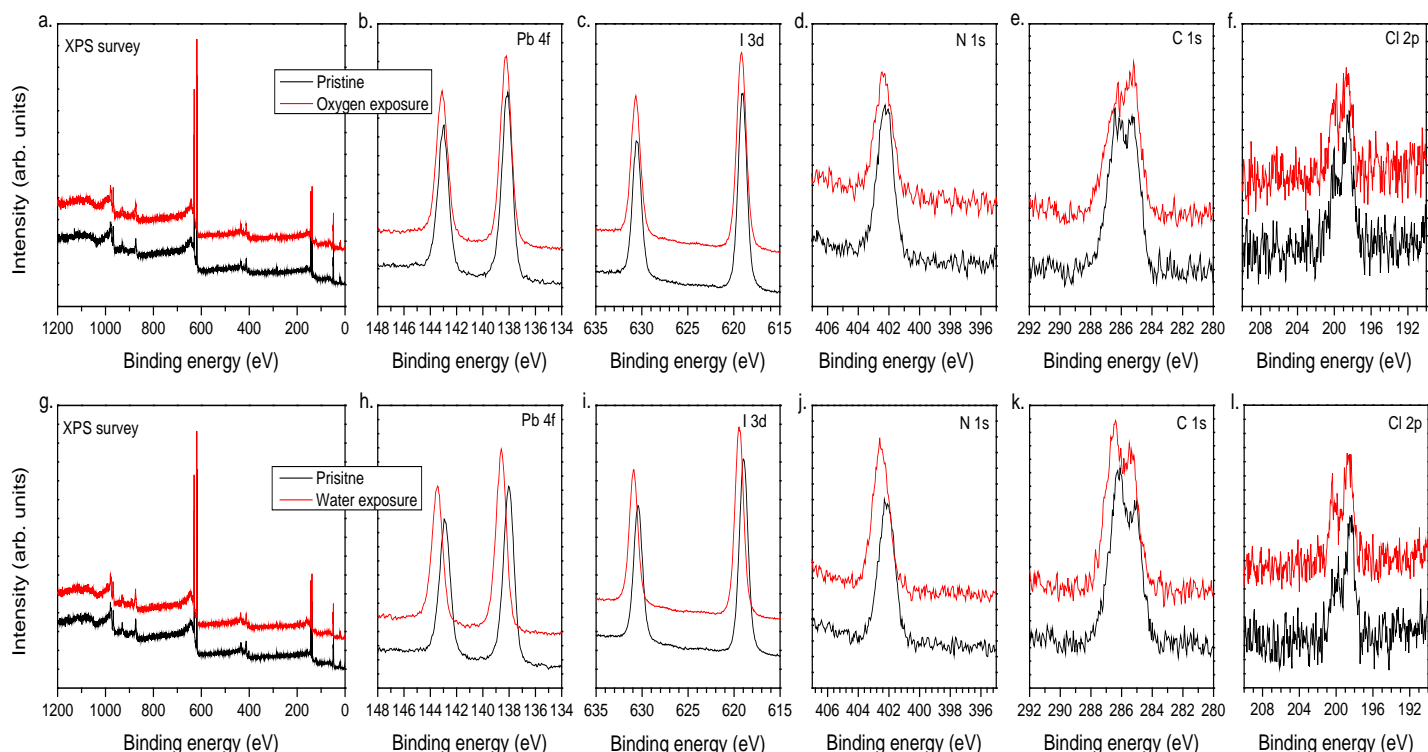

Figure S5. XPS survey spectra and Pb4f, I3d, N1s, C1s and Cl2p core level spectra of the $\mathrm{CH}_{3} \mathrm{NH}_{3} \mathrm{PbI}_{3-\mathrm{x}} \mathrm{Cl}_{\mathrm{x}}$ films before and after (a-f) oxygen and (g-l) water exposure. 

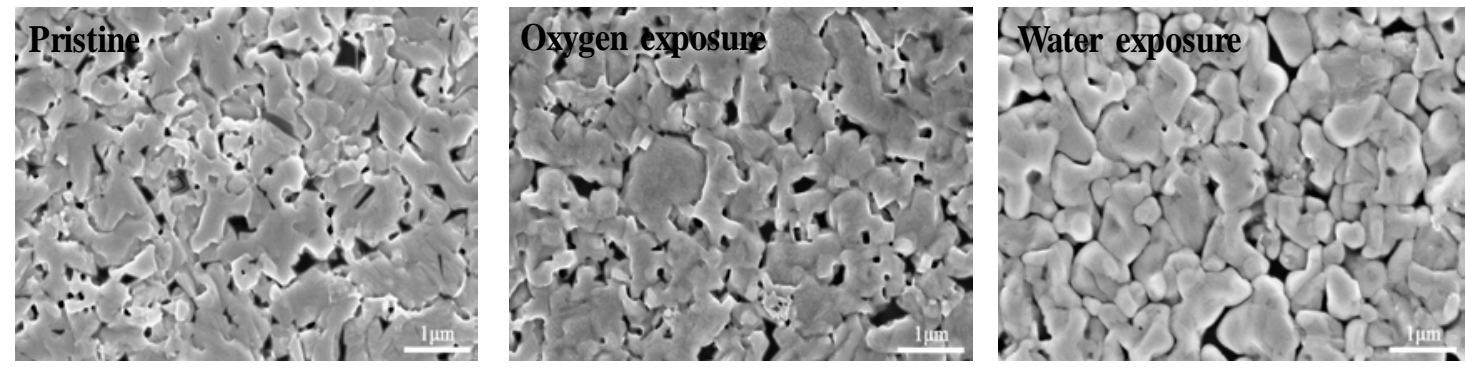

Figure S6. Surface morphologies of the pristine, oxygen exposed and water exposed $\mathrm{CH}_{3} \mathrm{NH}_{3} \mathrm{PbI}_{3-\mathrm{x}} \mathrm{Cl}_{x}$ films. 


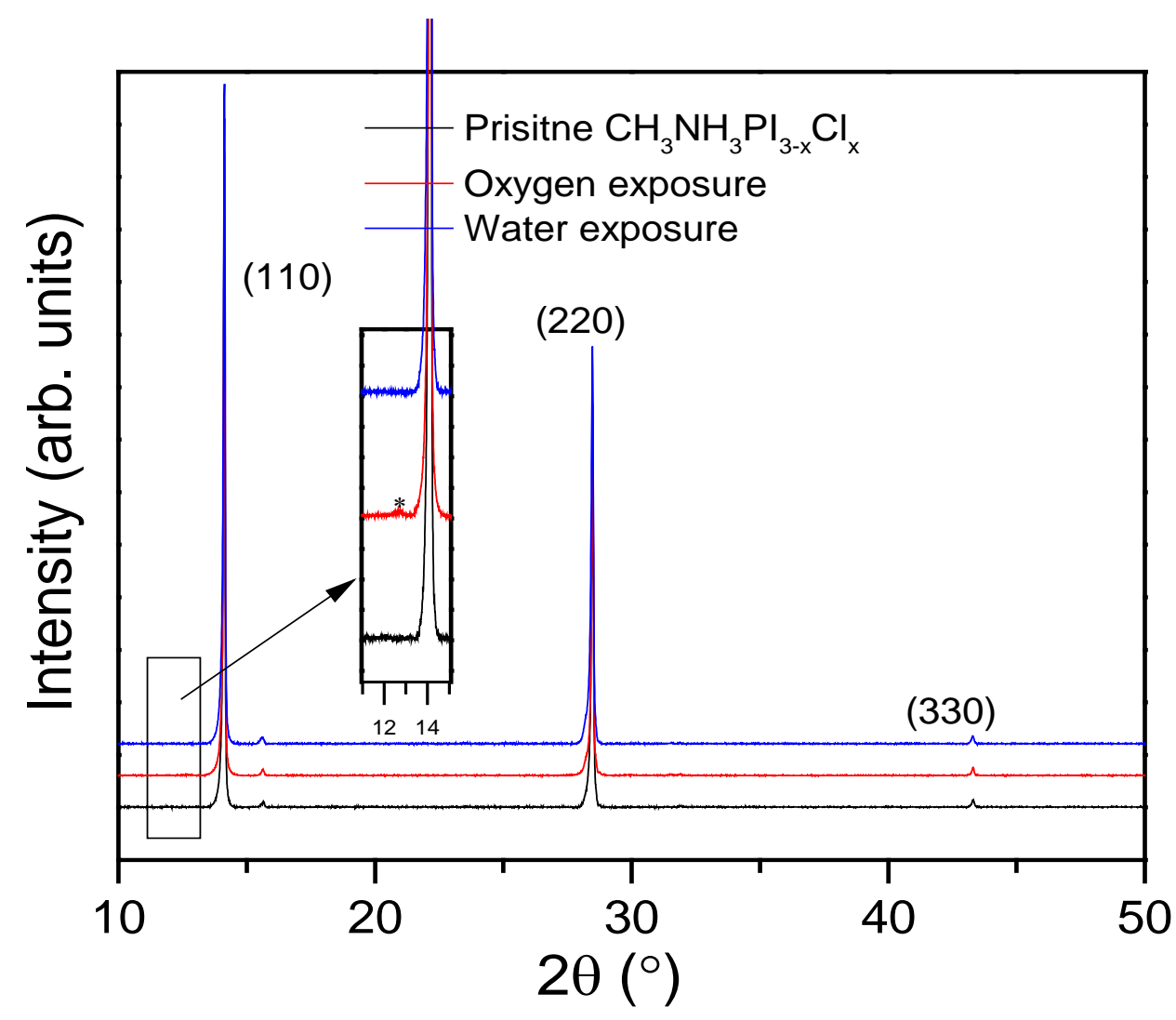

Figure S7. X-ray diffractograms of the pristine, oxygen exposed and water exposedCH3NH3PbI $3-x$ Clx films. 


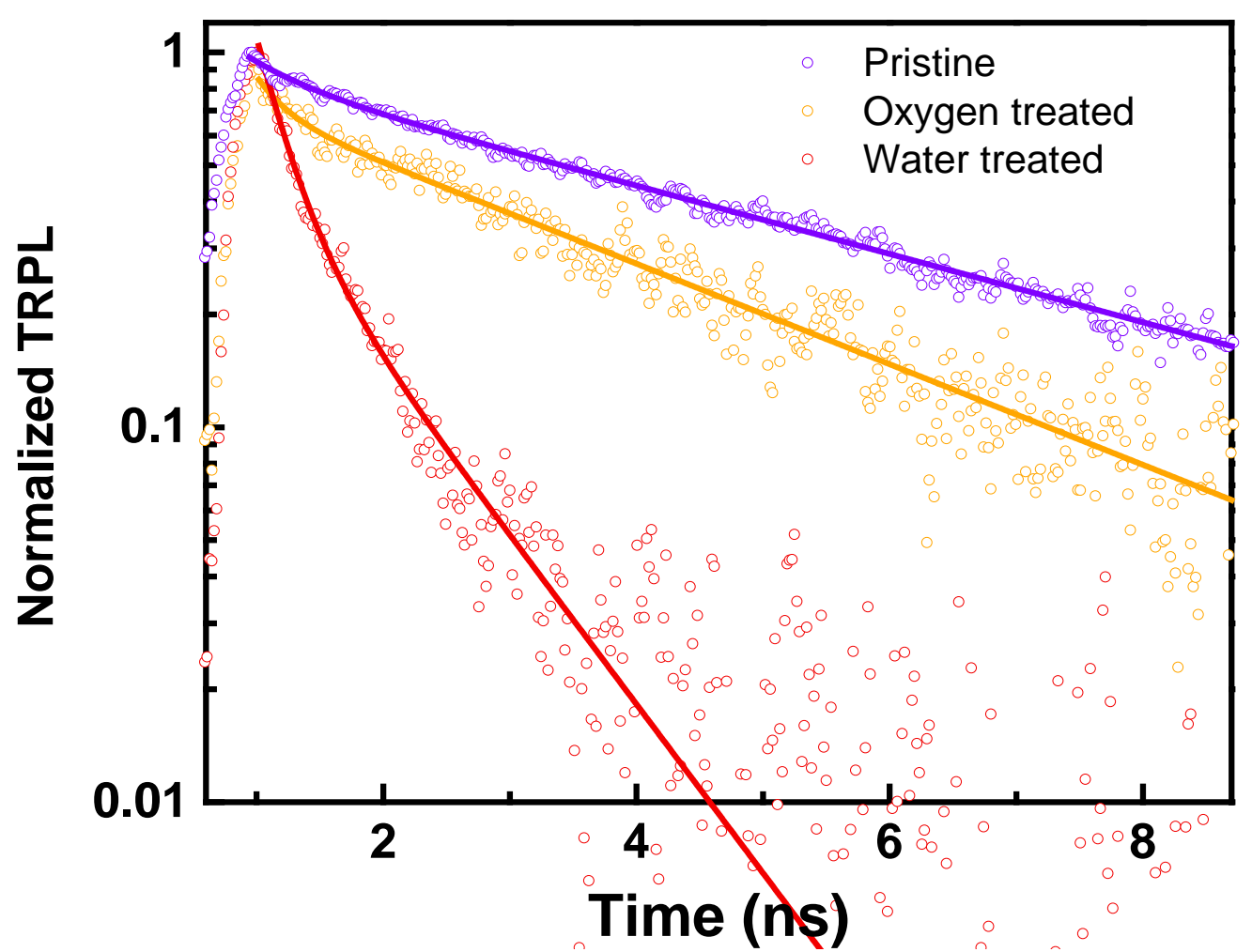

Figure S8. Photoluminescence decay kinetics of the $\mathrm{CH}_{3} \mathrm{NH}_{3} \mathrm{PbI}_{3-\mathrm{x}} \mathrm{Clx}$ film before (violet symbols) and after oxygen (yellow symbols) and water (red symbols) exposure. 


\section{References}

1. D. Alpert, New Developments in the Production and Measurement of Ultra High Vacuum, J. Appl. Phys. 24, 7 (1953), 860-876 